\title{
STEM Education and Problem-Solving in Space Science: A Case Study with CanSat
}

\author{
Jose Contente *; Cecília Galvão
}

Institute of Education, University of Lisbon, 1649-013 Lisbon, Portugal; cgalvao@ie.ulisboa.pt (C.G.); contente.jose@ie.ulisboa.pt (J.C.)

* Correspondence: contente.jose@ie.ulisboa.pt

Jose Contente- ORCID: 0000-0002-3213-5271 Cecília Galvão- ORCID: 0000-0002-0347-4872

\begin{abstract}
Research has shown that hands-on projects promote stem education, namely, via problemsolving. CanSat, literally 'satellite in a can', is a stem educational project promoted by the European Space Agency. This paper addresses this issue by researching this STEM project, which demonstrates how problem-solving can be achieved in secondary-level students within the framework of the CanSat. We use qualitative techniques of data collection and analysis. The results showed that students use sophisticated thinking strategies to process information within this interdisciplinary project: (a) cognitive testing, cognitive organization, cognitive regulation, and monitoring, in addition to computer language and physical-mathematical calculations, are cognitive and metacognitive behavior strategies revealed in the CanSat; (b) problem-solving was suggested as a specific model, where students' higher cognitive and metacognitive ordering processes deepen in project development; (c) computational, lateral, or divergent and convergent thinking were detected as thinking types of students associated with and mobilized in the course of problem-solving, The findings of this research have practical implications for STEM education in space science. Hands-on projects using problem-solving are an essential strategy to promote STEM education. Additionally, they are a starting point to promote meaningful learning and new thinking types.
\end{abstract}

Keywords: STEM education; problem-solving; thinking types; space science at school; CanSat

\section{Introduction}

In 1998, Professor Robert Twiggs of Stanford University conceived CanSat. After, CanSat became an international project of great popularity at schools and universities. The creator of CanSat associated him with several initial assumptions: 'a real spatial project is a right motivation for students; the aerospace industry's interest in having new frameworks with an understanding of the requirements of space projects, and space projects were applied in the courses of the master's program in astronautics' [1] (p. 2). Since 2011, European Space Agency (ESA) has been promoting an annual competition in Europe with high school students, which improves the acronym STEM (science, technology, engineering, and mathematics) as an educational project.

The term STEM is not new, nor is it the integration of subjects, such as mathematics and science. It was first referenced by the United States agricultural system in 1800, although it was the National Science Foundation of the United States that coined the acronym STEM in 1990 [2]. STEM education is an interdisciplinary approach that arouses curiosity and interest in students because it promotes the learning of specific concepts in practical activities where students apply science, technology, engineering, and mathematics in contexts, establishing connections between school, community, and the world of work and businesses, thus enabling the development of literacy and STEM skills to compete in the new economy $[3,4]$. In this study, we adopted a holistic view with several dimensions [5].

We based this article on a broader investigation conducted by the authors during two years (Y1 and Y2). We do not name the year of the study for confidentiality reasons. The 
literature on CanSat projects (literally 'satellite in a can') focuses on the description of the processes and components (hardware and software) of the satellite and, collaterally, on its educational advantages [6-8]. The lack of STEM studies on space technology in schools, particularly on students' ideas associated with the CanSat educational project, highlights the relevance of this research $[6,7,9]$. The Portuguese team that participated in the present study won the national and European competitions of CanSat.

In summary, we hope that this study can contribute to the construction of knowledge, be useful in the future practice of teachers, and make it possible to formulate new educational policies. Moreover, we have tried to understand how students think, and we also tried to find ways to develop students' thinking to meet the new conditions of the 21st century. Thus, the interest of researchers in better understanding problem-solving in this educational project, STEM-CanSat, led to the formulation of different research issues. In this article, we will address one of these issues:

'How do you process problem-solving in middle-level students within the scope of the STEM-CanSat educational project?

\section{Background}

\subsection{The Concept of the Problem}

The notion of a problem can lie on an axis that ranges from the individual's relation with the situation to the characteristics of the task itself. This study will focus on the unpredictable situations posed to students who solve problems [10]. It is also essential to understand the analysis and thoughts related to the tasks and phases of problem-solving $[11,12]$. In this paper, the notion of a problem from students' perspective is any task assigned to them that has no solution before being researched.

\subsection{Approach to Problem-Solving}

The analysis of a varied number of phase propositions for problem-solving shows cognitive, affective, and practical factors that transversely cross them until reaching solutions. These learning goals include the highest levels of active, reflexive, and innovative teaching and learning: (i) problem-solving heuristics, (ii) metacognitive knowledge, and (iii) creativity and originality $[13,14]$.

Problem-solving is one of the most critical forms of cognitive processing and a fundamental process in learning science and mathematics $[15,16]$. The ability to solve problems has been presented as one of the most critical cognitive competencies [17-19] or as a way of bringing real problems of science and technology into the classroom [20].

Today's globalized and technologically advanced world poses new questions to everyday life in a complex set of actions, multiple objectives, uncertainties, and environments that can change independently of measures to solve problems [21,22], requiring complex cognitions within the framework of solving complex problems (CPS) [23]. Additionally, Hung [24] focused on team-based complex problem-solving with a collective cognition perspective to understand the complexity of most real-world problems.

We link problem-solving to trial/error processes, insight, and heuristics, but also to the deep processing that, related to technology, reinforces students' metacognitive awareness according to the tasks and strategies they are involved in [25]. Schunn and Silk [26] show that problem-solving requires dealing with five major elements: procedural fluency, conceptual understanding, strategic competence, adaptive reasoning, and productive disposition.

For many in the learning process, there is a strong connection between learning and self-regulation $[27,28]$. This suggests that a student's ability to self-regulate is an essential and critical component of the problem-solving process. The student sets goals before the task, then reviews those objectives during the completion of the work and reflects on the learning experience associated with the specific function [28-30].

We adopt self-regulated learning as the use of cognitive, metacognitive, and resource management strategies that students use to regulate their cognition and control their 
learning $[27,28]$. Self-regulation is an internal process where the student develops thoughts, feelings, and actions (behaviors), and recognizes his or her strengths and weaknesses in the face of a task on the way to the desired goal [30].

The CanSat project appeals to these forms of thinking but, because of its nature, it deals with knowledge-rich problems because they require specific, relevant skills (previous knowledge), presupposing on a large scale the use of informal reasoning in the evaluation of the strength of the arguments, knowledge, and personal experience [31].

In short, the general principles of APS include problem-based, project-oriented, contextual, active, experimental, collaborative, and small-group learning, with a consilience connection between theory and practice, an appeal to interdisciplinary processes, and metacognition. Those perspectives pointed out three domains of competence: cognitive, intrapersonal, and interpersonal. Moreover, they show distinct sides of human thinking and build on previous efforts to identify and organize dimensions of human behavior [32].

\section{Methodology}

The study described here is qualitative, orientation to interpretation [33,34], and considered useful in evaluating students' reasoning and experiences in problem-solving activities. This descriptive and interpretative investigation focused on the understanding of multiple realities and required immersion in the field of study, for non-participant observation, for two years (exploratory phase and empirical study). CanSat is defined as a case study, assuming itself as a methodological approach to research a contemporary phenomenon in its context, as it occurs in the real world [34]. We developed a case study with a team participating in the CanSat. Students incorporate all CanSat systems into this satellite in the form of a cylindrical can with $115 \mathrm{~mm}$ height, $66 \mathrm{~mm}$ in diameter, and a mass weighing $350 \mathrm{~g}$. The challenge of the CanSat contest/competition comprises the construction of the satellite, launch up to $1000 \mathrm{~m}$ altitude, and safe landing. After the separation from the launching rocket, at $1000 \mathrm{~m}$, a scientific experiment is conducted during the controlled descent of the satellite. A receiver station created and operated by the teams in this primary mission collects signals by telemetry (Figure 1).

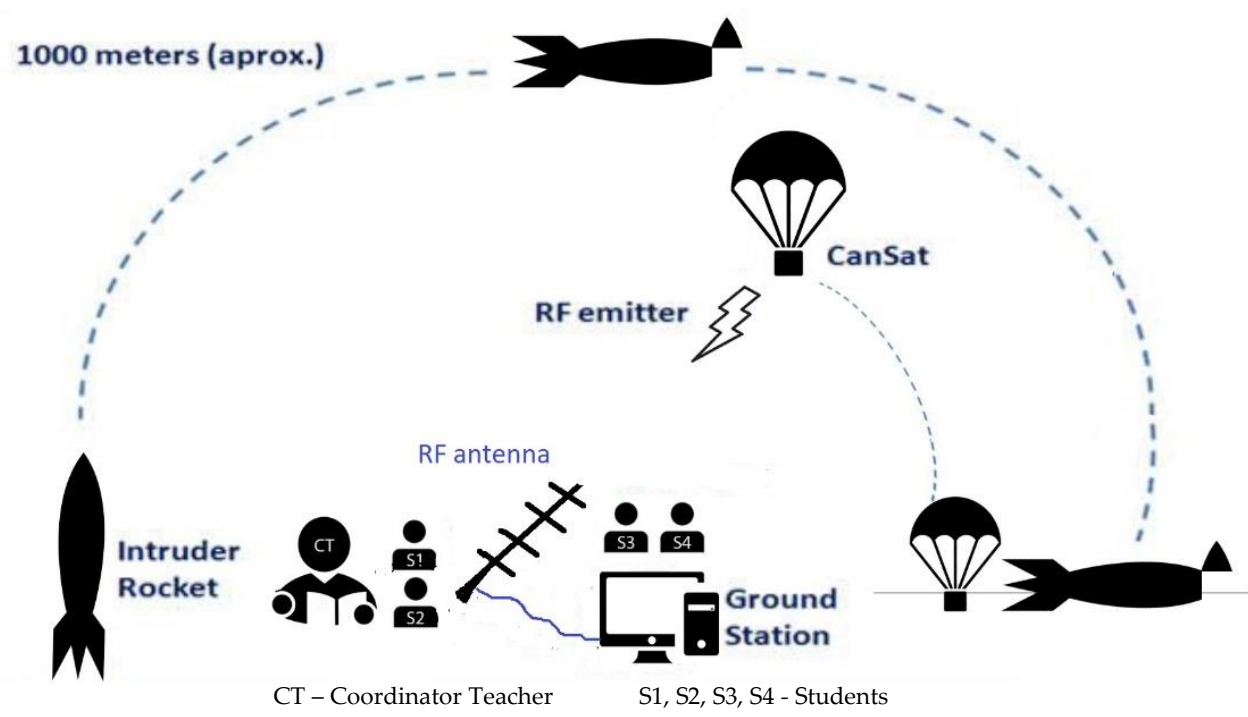

Figure 1. CanSat competition launch and landing. The team Coordinator Teacher (CT) and students (S1, S2, S3, S4)

There is also a secondary mission that reflects the innovative aspects displayed by each team. The final assessment of each group is carried out by a jury that will distinguish the compliance with the requirements of the primary mission and the quality/innovation achieved in the secondary mission. 
This work aims to identify the most significant characteristics of the problem-solving approach adopted by students in this project. As a qualitative study, this research does not intend to establish generalizations, but the transferability of results in similar contexts is allowed $[33,34]$.

\subsection{Participants}

Four students (S1, S2, S3, and S4) were grouped to form the study's participating team. The tasks were distributed by the coordinating teacher (CT), who took into account the interests and skills of the students. The study participants were between 18 and 19 years old. The CT had 20 years of service and experience of participation in similar projects.

All students had previous knowledge in mechanics, welding, electronics, programming, and physics. The team worked from November to July after school and during home hours. On average, students spent three to four hours a day working on the project during this period. One of the team members had a specific mission (team leader). He was responsible for communicating the results of the primary and secondary missions of the project (in Portuguese and English) to the public and the jury of national and European competitions.

\subsection{Data Collection}

Qualitative instruments, such as questionnaires, interviews, documentary analysis, and direct observation, were used to understand the resolution of problems in the CanSat project. As described below, these instruments aimed to obtain a deeper understanding of the contribution of different factors involved in problem-solving by the students participating in the object of this study - the CanSat project.

\subsubsection{Instruments}

To know and understand the students' ideas and how they solve the problems, it was decided that the study would use qualitative techniques for data collection and analysis: questionnaires (Q1 and Q2) with semi-open questions and interviews with the students during problem-solving activities [35,36]. Additionally, we used the documentary analysis of material produced by the students [34]. In this research article, we refer to the Final Design Review (FDR) (APPENDIX 1). It is a personal report elaborated from all four students. S1, S2, S3, and S4 built this report as one of the requirements of the CanSat competition standards.

The complete interviews were recorded and fully transcribed for full access to the discourses. They were then submitted to a categorical analysis to identify the significant elements to organize the initial entropy of the raw data. This technique was used to understand what is behind the meaning of words while looking for a critical revelation based on an in-depth reading of the data [35,36].

The construction of the instruments was based on the application of a questionnaire applied in an exploratory study-one before the empirical study conducted with other Portuguese teams that competed at CanSat. This exploratory study allowed the measurement and validation of instruments by several high school teachers and a researcher at the University of Lisbon. The validity and reliability of the study were guaranteed either through multiple triangulation techniques used with the application of various instruments [37,38] or through the inductive analysis of interviews to identify the most significant and emerging traits, themes, and regularities of students' responses [34,38].

\subsubsection{Study Phases}

We developed the study in two phases: Phase I (project development - from November Y1 to April Y2) and Phase II (after the national competition until the European finalfrom May to July Y2). Observation of students by the researchers occurred during CanSat, from November Y1 to July Y2. This non-participant observation also included the 
presence of researchers in national and European competitions and the national and European finals of CanSat, held in Portugal in April Y2 and June Y2, respectively. Due to space limitations, this article mainly focuses on the data collected from students, which were useful in responding to the research question formulated in this article.

\subsubsection{Coding}

For the analysis of problem-solving data, the study used categories described in $[39,40]$. Zoller and Pushkin [40] outlined three categories according to cognitive abilities: (i) algorithms (ALG), (ii) inferior cognitive abilities (LOCS), and (iii) superior cognitive abilities (HOCS). This latter category represents the problems that students do not know; it represents problem-solving (not exercises) in research and making conscious decisions or complex and sophisticated thoughts. More specifically, the HOCS response category includes several criteria or levels: (i) selection of relevant information, (ii) analysis/evaluation of variables or causal relationships between the components of the problem, (iii) proposal of plausible solutions to problems, (iv) capacity to formulate hypotheses, and (v) development of skills to a high cognitive degree [40]. We use these categories because they have a relationship with problem-solving, which is the relevant focus of this research study.

During data coding, we adapted some of the categories [41] that encode cognitive and metacognitive strategies of behavior and self-regulation in problem-solving. We use both of these categories because they relate to problem-solving, which is a relevant focus in this research study.

In discussing the types of thinking, some authors widely recognized that most types of thinking involve solving problems as a cognitive activity [31]. Given the specificity of the research, some categories emerged from the analysis, such as those related to convergent/divergent or lateral thinking [42-44] and computational thinking [45-47]. Indeed, these categories were generated based on the empirical data in this study. References to duality in convergent/divergent or lateral thinking and computational thinking that emerged from the data interviews reveal the complexity and integration of different types of reasoning used by students in this project. These types of thinking emerge in this study with various meanings. In the first case, convergent thinking calls for appropriate instruments for specific measurements, margins of acceptable errors in the problem-solving process, the conformity between the outcome of a measure and theoretical prediction, and methodological commitments. These data were collected in the interviews and correspond to convergent (solution-directed) thinking. In a second dimension, when students reevaluate data or processes and seek new, imaginative, innovative, or creative solutions, as was the result of the project's secondary mission, they are in the field of divergent or lateral thinking. The heuristic solves problems that were also present in this project when students faced a problem from various angles without focusing on a unique look, corresponding to divergent or lateral thinking. Convergent thinking, being more conventional, is as important as divergent thinking, more linked to innovation for scientific advancement. [43]. Finally, the training of students - in particular in programming languages (Arduino) and electronics-seems to induce computational thinking. This is marked by schemes, drawings, diagrams, and flowcharts with 'input and output,' or as is the case in the ways of thinking students in the 'back-to-correct errors,' constituting present and decisive factors in the success of project development. This last assertion translates to the computational thinking that is a fundamental competence for students in the 21st century [46-48]. In summary, these categories associated with problem-solving emerged in the analysis of the interviews. They are assumed and reflected in the presentation and discussion of the results.

\section{Results}


In the next section, we discuss the findings in the context of existing research. This qualitative study aimed to investigate "how is problem-solving represented among secondary-level students in the context of the STEM-CanSat educational project?"

This discussion intends to improve our understandings of students' thinking, cognition, and metacognition within a STEM project such as CanSat. Moreover, there are implications for STEM education that the CanSat project reveals.

\subsection{Coding Strategic Behavior and the Level of Cognitive Abilities}

In Table 1, for example, some answers to two questions from questionnaires 1 and 2 (Q1 and Q2) applied to students (S1, S2, S3, and S4) in Phases I and II (PhI and PhII) are transcribed. This table synthesizes a strategic coding behavior regarding cognitive and metacognitive functioning and self-regulation strategy. 
Table 1. Excerpts from the answers of the four students (S1, S2, S3, and S4) to questionnaires 1 and 2 (Q1 and Q2).

\begin{tabular}{|c|c|c|}
\hline \multicolumn{2}{|c|}{$\begin{array}{l}\text { What were the main difficulties you felt in each of the phases you } \\
\text { were most involved in? How did you solve these difficulties? }\end{array}$} & $\begin{array}{l}\text { Cognitive and metacognitive behavior and self-regulation } \\
\text { strategy }\end{array}$ \\
\hline $\begin{array}{l}\text { S1Q1 } \\
\text { PhI }\end{array}$ & $\begin{array}{l}\text { '.. problems ... make the parachute withstand } 100 \mathrm{~kg} \text { of } \\
\text { force ... many resources such as reinforced seam and } \\
\text { reinforced holes... and teamwork' }\end{array}$ & Cognitive elaboration and organization \\
\hline $\begin{array}{c}\text { S2Q1 } \\
\text { PhI }\end{array}$ & $\begin{array}{l}\text { 'At the programming level ... trial and error but within } \\
\text { limits ... we know when the extreme is and ... the least ... } \\
\text { we deal with those two points to solve the situation.' }\end{array}$ & Cognitive organization and metacognitive regulation \\
\hline $\begin{array}{l}\text { S3Q1 } \\
\text { PhII }\end{array}$ & $\begin{array}{l}\text { 'At this stage, I still had little difficulty with my role (to } \\
\text { make and manage a web page and a Facebook page), } \\
\text { but the electronic presentations of the team I feel will be } \\
\text { complex.' 'I have support in the group' }\end{array}$ & Cognitive organization \\
\hline $\begin{array}{c}\text { S4Q1 } \\
\text { PhI }\end{array}$ & $\begin{array}{c}\text { 'Programming ... my knowledge in Information and } \\
\text { Communication Technologies ... fall into the data } \\
\text { processing component'... }\end{array}$ & Cognitive organization and elaboration \\
\hline $\begin{array}{c}\text { S1Q2 } \\
\text { PhII }\end{array}$ & $\begin{array}{l}\text { 'Connecting the transceiver and frequency } \\
\text { programming' ... Resorting to attempts by making } \\
\text { "virtual" pins on the plaque and precision welding.' }\end{array}$ & Cognitive organization and metacognitive regulation \\
\hline $\begin{array}{c}\text { S2Q2 } \\
\text { PhII }\end{array}$ & $\begin{array}{l}\text { 'Radiation sensors were the biggest problem' '... I did a } \\
\text { lot of research and testing.' } \\
\text { '...and collaboration of the group.' }\end{array}$ & Cognitive organization and metacognitive regulation \\
\hline $\begin{array}{l}\text { S3Q2 } \\
\text { PhII }\end{array}$ & $\begin{array}{l}\text { 'Stress school and everything else ... schoolwork, } \\
\text { managing time to train for presentation to jurors in } \\
\text { English. I ended up having a crush because of the } \\
\text { pressure before the European competition... lots of tests, } \\
\text { work, and the presentation was a lot all together'. }\end{array}$ & Cognitive organization and elaboration \\
\hline $\begin{array}{c}\text { S4Q2 } \\
\text { PhII }\end{array}$ & $\begin{array}{l}\text { 'Ignorance of LabView's programming language... } \\
\text { taking a long time to learn and study the language ' }\end{array}$ & Cognitive organization and metacognitive regulation \\
\hline
\end{tabular}

The questions focus on how students value solving problems and indicate cognitive behaviors, metacognitive behaviors, and self-regulation strategies [41]. The cognitive organization, metacognitive regulation, cognitive elaboration, and organization are cognitive and metacognitive behavior strategies revealed in problem-solving in the CanSat project (Table 1). They correspond to self-regulation strategies in learning [49] and include cognitive, metacognitive, and resource aspects [28]. According to [49], 'self-regulated learning strategy' is the 'actions directed at acquiring information and skill that involve agency, purpose (goals), and instrumentality self-receptions by a learner' (p. 615). Table 1 shows that students have cognitive and metacognitive behavior and self-regulation strategies when solving complex problems. These self-regulation processes take the form of cognitive skills, such as goal awareness, self-monitoring of the progress of objectives, and problem-solving to better achieve the goals [50,51]. Although collaborative work in a nonformal context was a dominant trait of the development of the CanSat project, each student had more specific tasks that were reflected in the responses presented and discussed in this section. There was mutual help intragroup or active collaboration among the team members (Table 1).

Table 2 shows categorization to understand the methods of problem-solving and the level of cognitive abilities [40] identified in both questionnaires (Q1 and Q2) and applied to students S1, S2, S3, and S4. 
Table 2. Cognitive and metacognitive behavior and self-regulation strategies.

\begin{tabular}{|c|c|c|c|c|c|}
\hline & Problem Identification & Student & Resolution Method & Level & Category \\
\hline \multirow[t]{4}{*}{ Q1 } & Parachute & S1 & $\begin{array}{l}\text { 'Operative (physical-mathematical } \\
\text { calculations) and controlled } \\
\text { experiments.' }\end{array}$ & 5 & HOCS \\
\hline & Programming & S2 & $\begin{array}{l}\text { 'Attempted trial-error... but within } \\
\text { limits... go back to correct the error.' }\end{array}$ & 5 & HOCS \\
\hline & English team results presentations & S3 & $\begin{array}{c}\text { 'ICT results integration and use } \\
\text { bilingual communication and } \\
\text { language.' }\end{array}$ & 5 & HOCS \\
\hline & Data processing & S4 & 'ICT use.' & 5 & HOCS \\
\hline \multirow[t]{4}{*}{ Q2 } & Programming & S1 & 'Trial-error balanced.' & 5 & HOCS \\
\hline & Sensors & S2 & $\begin{array}{l}\text { 'Research and many tests, schematics, } \\
\text { drawings with input-output.' }\end{array}$ & 5 & HOCS \\
\hline & $\begin{array}{l}\text { Manage a web page and a Facebook } \\
\text { page. Fully monitor the project }\end{array}$ & S3 & $\begin{array}{c}\text { 'Content Update } \\
\text { Website speed testing and information } \\
\text { integration.' }\end{array}$ & 5 & HOCS \\
\hline & Programming for data processing & S4 & 'Research and study.' & 5 & HOCS \\
\hline
\end{tabular}

All students reveal marks of HOCS in a specific task in which one is responsible. Thus, this STEM project reveals that students mobilize critical, systemic, and evaluate thinking, question-asking, and decision making. Therefore, this is a practical and specific case that sustainably permits what some authors believe should be achieved [52]. We can also see that CanSat represents authentic, real-world problems that require an interdisciplinary approach and different solutions. The open-ended problems with different resolutions allow students to enhance their content knowledge and higher-order thinking skills $[53,54]$.

\subsection{Student's Interviews}

In this section, we show excerpts from transcripts of Interviews 1 and 2 (Int1 and Int2) conducted on students (S1, S2, S3, and S4), where some types of thinking emerged from data analysis are identified and analyzed. The examples presented show different phases of project execution and simultaneously the most valued phases in interviews with the four students. This valuation binds to the specific functions allocated to each student.

Student S1 in Int1 and Int2, referring to problem-solving in parachute construction, stated:

'We started with a very robust and huge parachute ... when we went to test it, he could not stand the $100 \mathrm{~kg}$... there is a standard speed that he has to meet on the descent ... was too fast ... we had to reduce the parachute area' (Int1) and 'the size of the parachute wires ... when the wires were cut, some had $1 \mathrm{~cm}$ difference ... enough not to work ... everyone has to endure about 8 kilos and such' (Int2).

These answers reveal the appropriate use of instruments for precise measurements, margins of errors acceptable in the problem-solving process, the conformity between the outcome of a measure and theoretical prediction, and methodological commitments. They are operations directed at the solution, typical of convergent thinking.

S2 student uses various types of thinking. In Int1, the student uses convergent thinking when identifying the problem that values and seeks the solution by sketching a hypothesis:

'... GPS was giving some problems ... the hypothesis was in Arduino programming. Computational thinking is also inscribed in the formulation: ... in Arduino programming ... We checked that there was a mistake ... a keychain ... poorly done ... was enough to create conflict'. 
S2 calls for knowledge of Arduino's computer and electronic language, where it identifies the sequence that solves the problem by changing a programming signal when it said: 'a keychain ... poorly done'.

At Int2, student S2 stated:

'Radiation sensors ... were the biggest problem ... I spent many hours ... it took time to conclude that the problem was in the sensors, that ... was too sensitive and (how will I explain?) reached the maximum level, for example, with minimum values'.

Thus, student S2 reevaluated data and processes and sought new, imaginative, innovative, or creative solutions - that is, situations identifying divergent or lateral thinking.

Student S3, the team leader, had communication functions of the results-integrated data, and modeled them computationally to be presented to the juries of the competitions: In this description, inscribed in Int1 and Int2, convergent thinking and divergent or lateral thinking emerge. At Int1, there is a search for solutions:

'I always try to see if the problems are the same as mine, and I see if problemsolving varies. I try to see if the cause of the problem is connected ... Moreover, I try what else I think can solve it, and if I do not, I try another way'.

On the other hand, S3 was more accurate in Int2 when they reevaluated data and processes and sought new imaginative, innovative, or creative solutions - that is, situations identifying divergent or lateral thinking. These characteristics are present in the following excerpt from Int2, when S3 states the following:

'The biggest problem ... the presentation, it was the fact that I had to know and integrate many things I did not know. It is not a matter of memorizing, it was knowing ... the light sensors ... had never heard ... Many mathematical calculations that the teacher also explained, including the world of the radiance of light ... coordinates, how CanSat coordinates were calculated ... as he walks. If the jury asked me ... as a leader, I did not think good ... pass this on to another. I had to answer for myself, even though I had lived in Australia.'

This student, S3, was responsible for the overall presentation of the project (team leader) in Portuguese in the national competition and English in the European competition. He performed the theoretical learning of the development of the project and the final product, in terms of the use of information and communication technologies (ICT), without, however, having actively participated in laboratory or field activities. The researchers observed excellent presentation training carried out by this student, with the support of an English teacher from the school and the CT of the project. Moreover, student S3 trained alone at home. Student S3 was the member who promoted the integration and coordination of the group's actions. His linguistic skills were evidenced in coding and decoding the language of his peers and the final results of the project. With a scientific language marked by different concepts, S3 presented verbal, coherent, and syntactically organized discourse [19].

In short, S3 was responsible for submitting the evaluation of the project to the juries of the national and European competitions and played a crucial role in the success of the project. The efficient and bilingual verbal performance of technical and scientific aspects during the final phase of the project presentation allows us to infer the mastery of S3's metacognitive skills. All the integration and coordination of the results achieved by the group, at each stage of the project's development, required an internal language that implied a complex intellectual activity [19].

S4 let convergent thinking and divergent or lateral thinking emerge in Int1. Indeed, in an attitude directed at a solution, S4 says in Int1: '...first, research on similar problems ... through the internet ... I even answered questions with my teachers... I survey the various ways I can solve problems and then run'. However, he adds, 'but what if it does not work out, I try otherwise and so on.'. Thus, he admits that he reevaluated data and processes and sought new imaginative, innovative, or creative solutions - that is, situations 
identifying divergent or lateral thinking. At Int2, S4 has an elaborate global description, where the use of three types of thinking emerges. First, at Int2, S4 identifies the problem and seeks the solution (convergent thinking): '...we had a problem, the GPS took a long time to fix ... we have got a solution.' They then guide and concretize, showing that they have reevaluated data and processes to achieve new imaginative, innovative, or creative solutions, that is, situations identifying divergent or lateral thinking. This aspect is present in the statement still concerning the GPS problem:

'... demonstrate the CanSat trajectory with a few points ... by calculating an Excel sheet through azimuth and elevation. Using these two values, I calculated the coordinates and represented them in the 3D chart ... I created the chart in Excel ... A series of Brainstorming.'

S4 ends the narrative in a prism that integrates the three types of thinking. This happens when S4 verifies the use of programming and electronic languages, or how the student thinks about 'going back to correct errors' as they attest in the following sentences:

'We have to think ... and then make this thought translate into the computer program that we are using ... I spent much time ... a week and a half ... including weekends, at home working on it, sometimes returning to the beginning.'

S4 had to reevaluate data and processes and sought new imaginative, innovative, or creative solutions; that is, situations identifying divergent or lateral thinking. This dimension is reflected in the path of resolution of the GPS problem, in which S4 refers:

'... Excel is very limited at the graphics level ... we have to manipulate it with macros, and with our knowledge ... we have 3D charts, but it is not, for example, with three values. We have one point. It was necessary to create the other two to make the 3 points manually ... transform planimetry into three dimensions ... to also present this as a bonus mission.'

As it was said, it is in the secondary mission of the project that students demonstrate the innovative character of their project. In this case, S4 illustrates the complexity of using three types of thinking in solving a real problem that required thinking abilities directed at the solution (convergent thinking), the creation of new solutions in a heuristic way, noted when the student faced the problem from various angles without focusing on a single focus (divergent/lateral thinking), and used programming and electronic languages. As pointed out, this last dimension reveals computational thinking, indispensable in the new skills of students in the 21st century, which require new policies and practices.

\subsection{Documentary Analysis}

In the context of the documentary analysis, we reproduced an excerpt of the students' report (FDR), which describe the initial statement of a test performed to verify the tensile strength of the parachute:

'... suspension of the parachute using a ball placed inside it, connected to a cable, which, in turn, was attached to a mobile crane ... The wires existing at the lower end of the recovery system were, in turn, connected to two standard weights 50 $\mathrm{kg}$ each ... The lifting of the mobile crane allowed the suspension of the system with a slightly higher traction force than the required of $100 \mathrm{~kg}$ (standard weights + belt mass that connected the weights to the recovery system).'

Moreover, using this documentary analysis below, we transcribed the experimental protocol used for parachute testing, namely, for the TRACTION FORCE TEST.

\subsubsection{Experimental Procedure}

The experimental procedure included a mass suspension - slightly above $100 \mathrm{~kg}-$ according to the setup shown in the previous paragraph, over $10 \mathrm{~min}$.

\subsubsection{Results}


Two experiments were carried out on May Y2, in which the following was observed:

Test 1 -The first trial was stopped a little before reaching the two-minute mark due to the breakage of the cables linking the spherical ball to the crane. The recovery system per se did not suffer any damage, and therefore, another test could be performed after improving the connection's strength (test 2).

\subsubsection{Tensile Force Test}

Test 2-In this test, the load was suspended about $20 \mathrm{~cm}$ above the ground for a period (timed with a chronometer) of $10 \mathrm{~min}$. We did not recorded any incidents during the test run (e.g., sounds which pointed to rupture of the parachute and/or coupling system).

\subsubsection{Conclusions}

Given the above, it is considered that the proposed recovery system meets the tensile strength requirements specified under the CanSat competition $1000 \mathrm{~N}$.

This test includes experimental procedures that present careful planning (initial statement and testing) with scientific significance. The competencies of scientific processes thus play an essential role in the process of evolution and conceptual development developed in problematic situations and activities that promote students' interest $[55,56]$.

\section{Discussion}

The results indicate that problem-solving in the CanSat project presents different methods and a complexity that manifests itself in higher cognitive abilities (HOCS), illustrated in Table 2, in addition to a favorable collaborative environment and a non-formal context. HOCS represents the answers to the problems that students do not know and point to problem-solving (non-exercises) for research and conscious decision making. HOCS translates superior cognition or complex and sophisticated thinking $[39,40]$. Besides, hands-on work, if utilized well, promotes HOCS and problem-solving development [40].

The results entered in Tables 1 and 2 reveal that students use diversified and sophisticated strategies to process information, namely, Internet research, analysis and synthesis of relevant information, and appropriate theoretical knowledge to make sense of the data collected. As for troubleshooting modes, students present several more operational procedures, such as mathematical and physical calculations and the use of ICT, activities that require investigations and experiences, content-update processes, integration of results, and a 'goal-error attempt' processes. 'Attempted trial-error... but within limits' or 'trialerror balanced' reveals the care for not damaging electrical material, which is a high-level cognitive monitoring strategy (Table 2). These self-regulation processes, such as 'marked error attempts' (Table 2), are crucial in learning because they bring the student's attention to and warn of material failures and their resistance limits so that they do not cause damage. In the metacognitive regulation identified, students reorient and restore behaviors toward the solution, such as when they say they return to review their work or 'go back to correct the error' (see Table 2).

In summary, the results of Tables 1 and 2 show different methods of problem-solving in the CanSat educational project that correspond to different cognitive and metacognitive strategies used by students and also show that students mobilize several skills associated with the complexity manifested in high-grade cognitive abilities (HOCS - higherorder skills). In the context of its complexity, the CanSat project, therefore, revealed that it called for a diverse set of cognitive, metacognitive, self-regulation strategies adjusted to the requirements placed on the students at each stage of satellite construction and presentation of results.

In terms of the analysis interviews, triangulation with Table 2 also reveals that the narratives expressed in the excerpts of Int 1 and Int 2 to the four students (S1, S2, S3, and S4) manifest the presence of higher-order cognition (HOCS) or complex thought. This dimension is revealed in the selection of relevant information, in the analysis/evaluation of 
variables or causal relationships between the components of the problem, in the presentation of proposals for plausible solutions to problems, and in the capacity to formulate hypotheses [40]. Moreover, the interviews revealed care for not damaging electrical material, which is a high-level cognitive monitoring strategy. These self-regulation processes, such as 'marked error attempts', are crucial in learning because they bring the student's attention to and warn of material failures and their resistance limits so that they do not cause damage. In this investigation, the process of self-regulated learning is similar to other research $[27,28,30,50,51]$.

In the practical activity, the students participated actively and autonomously in constructing the knowledge they acquired with the use of the scientific method. These practical activities also allowed the presentation of problematic situations, quantitative analyses, and forms of measurement [57]. It is accepted that within this CanSat project, the interpretation is markedly holistic, where scientific processes are understood as forms of thought and action that integrate and interpenetrate as a whole. These scientific processes interact in a creative network of more complex thought procedures and strategies designed to solve certain problematic situations [58]. Students, when they observed, planned the investigation, interpreted the results, drafted the report, and communicated or participated in group discussions, had to resort to some previous content or knowledge, as well as the interaction between this knowledge and the processes. At this point, we can reinforce the presence of HOCS, cognitive, metacognitive behavior, and self-regulation strategy linked with the use of the scientific method. In addition to this data triangulation, which increased the trustworthiness of this study, CanSat reveals multiple dimensions that are very advantageous in STEM education projects.

In summary, the group of students in this study who achieved success in the national and European competitions of the CanSat project showed a high level of cognitive and metacognitive skills, as well as the ability to use and adapt convergent thinking to divergent or lateral thinking, thus, reflecting flexibility or brain plasticity. The different types of thinking (divergent or lateral, convergent, and computational) that emerged from the analysis of the results allow us to perceive the complexity of CanSat and the mobilization of students' strategies in problem-solving. In the case of this project, there was a high degree of abstraction and integration and reliable prior knowledge about programming, electronics, physics, mechanics, and welding that were determining and useful factors in solving problems during the development of the project. CanSat also showed that it was a project where communication skills (in Portuguese and English) were crucial for evaluating the entire project in the framework of a national and European competition. This project presents characteristics that fall within the literature review and do not summarize to a single perspective. It is best understood in a holistic view because it inscribes and implies multiple strands, as in similar research activities. CanSat is an educational STEM project that introduces a new perspective different from the prevalent categories collected in a recent study [59]. Moreover, CanSat, because it is an interdisciplinary STEM education project, has not focused on the traditional problem-solving approach described in the literature. The STEM approach is used throughout the entire project because students use, integrate, and deepen various previous scientific knowledge during the different phases of CanSat execution. Additionally, this CanSat project incorporates several dimensions, including scientific methods, that not only imply how students think but also allow us to find new ways to develop students thinking within the requirements of the 21st century $[32,60]$. In the CanSat project, the integration processes of knowledge and communication skills are part of this last perspective. Thus, within the framework of STEM education, problem-solving in the CanSat project revealed the advantages of interdisciplinarity and a holistic view.

Previous studies show various types of thinking [42-48]. Similar results were found in the current investigation. Additionally, dual thinking seems to be the main factor in the project's success. This statement is according to the notion of advanced scientific thinking $[43,44]$. Moreover, this study has a holistic perspective, which is a new vision of the CPS [21-24,61] and other potentialities of the CanSat [62]. 
In short, the CanSat project revealed, therefore, within its complexity, references to duality convergent/divergent or lateral thinking and computational thinking. These types of thinking emerged from the data interviews and reveal the complexity and integration of different methods of reasoning used by students in this project, adjusted to the requirements placed on students in each phase of satellite construction and their presentation of results.

The results of this study recommend the use of problem-solving projects in STEM education to promote meaningful learning that reduces the barrier between school and real life through educational practices anchored in success factors and metacognitive strategies. It is, above all, a project that highlights different ways of developing students' thinking within the framework of the imperatives and emergencies of the 21st century.

The transferability of the study may be related to new advances in emerging areas, such as artificial intelligence, robotics revolution, and drones. These areas are also new challenges and opportunities for STEM education in 21st-century schools. As we have seen in the recent coronavirus pandemic, interdisciplinarity and problem-solving in a collaborative context can be useful tools for better answers in the scientific community. STEM education may be the right approach to construct these useful 21st-century skills). Teaching and learning in STEM education in new areas are complex, and much more research work is to be pursued in the future.

\section{Conclusions}

To answer the research question, 'How do you process problem-solving in middlelevel students within the scope of the STEM-CanSat educational project?', we indicate the following dimensions:

(i) Problem-solving methods in the CanSat project have a strong connection with cognitive and metacognitive strategies; (ii) students used different types of thinking that reveal high brain plasticity and cognitive abilities demonstrated in the collaborative environment and non-formal context developed at CanSat (iii) the students revealed an ability to use the scientific method in problem-solving; (iv) language skills were a determinant intragroup, for collaborative work/looking for solutions, and in the presentation of the results, linked to the existence of bicultural and bicognitive aspects, in particular, of the student who assumed this specific task. This study advocates integrated STEM education that emphasizes learning skills, such as technical language involvement, discernment of reliable sources of information, interpretation of qualitative representations or statistics, and communication of results.

Author Contributions: Conceptualization, J.C. and C.G.; methodology, J.C. and C.G.; validation, C.G.; formal analysis, J.C. and C.G.; investigation, J.C. and C.G.; data curation, J.C. and C.G.; writing-original draft preparation, J.C.; writing - review and editing, J.C. and C.G.; visualization, J.C.; supervision, C.G. All authors have read and agreed to the published version of the manuscript.

Funding: This work had no funding.

Institutional Review Board Statement: This study was conducted according to the guidelines of the Declaration of Helsinki and approved by Instituto de Educação da Universidade de Lisboa.

Informed Consent Statement: Informed consent was obtained from all subjects involved in the study.

Data Availability Statement: The data presented in this study are available on request from the corresponding author.

Conflicts of Interest: The authors declare no conflicts of interest.

\section{References}

1. Twiggs, R. Space engineering project-based learning by working real space programs. In Proceedings of the 2002 American Society of Engineering Education Annual Conference \& Exposition, Annual Conference, Session 1709, Montreal, QC, Canada, 16 June 2002. Available online: https://peer.asee.org/10474 (accessed on 11 December 2021). 
2. Ostler, E. 21st Century STEM Education: A Tactical Model for Long-Range Success. IJAST 2012, 2, $28-33$. https://doi.org/10.30845/ijast.

3. Bybee, R.W. The Case for STEM Education: Challenges and Opportunities; NSTA Press Book: Arlington, VA, USA, 2013; ISBN 9781-936959-25-9.

4. Johnson, C.C. Conceptualizing Integrated STEM Education. Sch. Sci. Math. 2013, 113, 367-368. https://doi.org/10.1111/ssm.12043.

5. Simarro, C.; Couso, D. Engineering practices as a framework for STEM education: a proposal based on epistemic nuances. Int. J. STEM Educ. 2021, 8, 53. https://doi.org/10.1186/s40594-021-00310-2

6. Cabuloglu, C.; Aykis, H.; Yapacak, R.; Çaliskan, E.; Agirbas, O.; Abur, S.; Soyer, S.; Turkmen, H.; Ay, S.; Karatas, Y.; et al. Mission analysis and planning of a CANSAT. In Proceedings of the 5th International Conference on Recent Advances in Space Technologies-RAST 2011, Istanbul, Turkey, 9-11 June 2011; IEEE: New York, NY, USA, 2011; pp. 794-799. https://doi.org/10.1109/RAST.2011.5966951.

7. Soyer, S. Small space can: CanSat. In Proceedings of the 5th International Conference on Recent Advances in Space Technologies-RAST 2011, Istanbul, Turkey, 9-11 June 2011; IEEE: New York, NY, USA, 2011; pp. 789-793. https://doi.org/10.1109/RAST.2011.5966950.

8. Johnson, C.C.; Burton, E.E.P.; Moore, T.J. STEM Road Map 2.0. A Framework for Integrated STEM Education in the Innovation Age, 2nd ed.; Routledge: London, UK; 2021, ISBN 9780367467524.

9. Colin, A. A pico-satellite was assembled and tested during the 6th CanSat Leader Training Program. J. Appl. Res. Technol. 2017, 15, 83-91. https://doi.org/10.1016/j.jart.2016.10.003.

10. Schoenfeld, A.H. Mathematical Problem Solving; Academic Press: Orlando, FL, USA, 1985; ISBN 978-0-12-628870-4.

11. Shulman, L.; Tamir, P. Research on teaching in the natural sciences. In Second handbook of Research on Teaching; Travers, R.M.W., Ed.; Rand-McNally: Chicago, IL, USA, 1973; pp. 1098-1148, ISBN 10: 0528618245.

12. Smith, M.U. Toward a Unified Theory of Problem-Solving: Views from the Content Domains; Lawrence Erlbaum Associates: Hillesdale, NJ, USA, 1991; ISBN 0-8058-0510-9.

13. Flavell, J.H. Metacognition and cognitive monitoring: A new area of cognitive-developmental inquiry. Am. Psychol. 1979, 34, 906-911. https://doi.org/10.1037/0003-066X.34.10.906.

14. Polya, G. How to Solve It: A New Aspect of Mathematical Method (No. 246); Princeton University Press: New York, NY, USA, 2004; ISBN 13: 978-0-691-11966-3

15. Anderson, J.R. Problem-solving and learning. Am. Psych. 1993, 48, 35-44. https://doi.org/10.1037/0003-066X.48.1.35.

16. Schunk, D.H. Learning Theories: An Educational Perspective, 6th ed.; Pearson: Boston, MA, USA, 2012; ISBN 10: 0-13-707195-7.

17. Frederiksen, N. Implications of cognitive theory for instruction in problem-solving. Rev. Educ. Res. 1984, 54, 363-407. https://doi.org/10.2307/1170453.

18. Piaget, J. The Construction of Reality in the Child, 1st ed.; Routledge: London, UK, 1954; ISBN 9781315009650.

19. Vygotsky, L.S. Interaction between learning and development. In Mind in Society: Development of Higher Psychological Processes; Cole, M., John-Steiner, V., Scribner, S., Souberman, E., Eds.; Harvard University Press: Cambridge, MA, USA, 1978 ; pp. 79-91. Available online: http://ouleft.org/wp-content/uploads/Vygotsky-Mind-in-Society.pdf (accessed on 10 December 2021).

20. Watts, M. Problem-Solving in Science and Technology; David Fulton Publisher: London, UK, 1994; ISBN $1853462705 / 9781853462702$

21. Fischer, A.; Greiff, S.; Funke, J. The process of solving complex problems. J. Probl. Solving 2012, 4, 19-42. https://doi.org/10.7771/1932-6246.1118.

22. Fischer, A.; Greiff, S.; Funke, J. The history of complex problem-solving. In The Nature of Problem-Solving: Using Research to Inspire 21st-Century Learning; Csapó, B., Funke, J., Eds.; OECD Publishing: Paris, France, 2017; pp. 107-121; ISSN $2076-9660$ (print), 2076-9679 (online).

23. Funke, J. Complex problem solving: A case for complex cognition? Cogn. Process. 2010, 11, 133-142. https://doi.org/10.1007/s10339-009-0345-0.

24. Hung, W. Team-based complex problem solving: A collective cognition perspective. Educ. Tech. Res. Dev. 2013, 61, 365-384. https://doi.org/10.1007/s11423-013-9296-3.

25. Schunk, D.H. Self-efficacy and cognitive achievement. J. Learn. Disabil. 1989, $22,14-22$. https://doi.org/10.1177/002221948902200103.

26. Schunn, C.D.; Silk, E.M. Learning theories for engineering and technology education. In Fostering Human Development through Engineering and Technology Education; Barak, M., Hacker, M., Eds.; SensePublishers: Rotterdam, The Netherlands, 2011; pp. 318. https://doi.org/10.1007/978-94-6091-549-9_1.

27. Pintrich, P.R.; Wolters, C.A.; Baxter, G.P. Assessing metacognition and self-regulated learning. In Issues in the Measurement of Metacognition; Schraw, G., Impara, J.C., Eds.; Buros Institute of Mental Measurements: Lincoln, NE, USA, 2000; pp. 43-97, ISBN 0-910674-45-0.

28. Schunk, D.H.; Ertmer, P.A. Self-regulation and academic learning: Self-efficacy enhancing interventions. In Handbook of SelfRegulation; Boekaerts, M., Pintrich, P.R., Zeidner, M., Eds.; Academic Press: Cambridge, MA, USA; 2000; pp. 631-649, ISBN 9780-12-109890-2.

29. Zimmerman, B.J. Self-regulated learning and academic achievement: An overview. Educ. Psychol. 1990, $25,3-17$. https://doi.org/10.1207/s15326985ep2501_2.

30. Zimmerman, B.J. Attaining self-regulation: A social cognitive perspective. In Handbook of Self-Regulation; Boekaerts, M., Pintrich, P.R., Zeidner, M., Eds.; Academic Press: Cambridge, MA, USA; 2000; pp. 13-39, ISBN 978-0-12-109890-2. 
31. Eysenck, M.W.; Keane, M.T. Cognitive Psychology: A Student's Handbook, 7th ed.; Psychology Press: Hove, UK, 2015; ISBN 9781315778006.

32. Li, Y.L.; Schoenfeld, A.H.; diSessa, A.A.; Graesser, A.C.; Benson, L.C.; English, L.D.; Duschl, R.A. On thinking and STEM education. J. STEM Educ. Res. 2019, 2, 1-13. https://doi.org/10.1007/s41979-019-00014-x.

33. Erickson, F. Qualitative methods in research on teaching. In Handbook of Research on Teaching, 3rd ed.; Wittrock, M.C., Ed.; MacMillan Reference Books: New York, NY, USA, 1986; pp. 119-161; ISBN 10: 0029003105, ISBN 13: 978-0029003107

34. Yin, R.K. Case Study Research: Design and Methods, 2nd ed.; Sage Publications: Thousand Oaks, CA, USA, $1994 ;$ ISBN 0803956630.

35. Bardin, L. L'analyse de Contenu, Quadrige Manuels ed.; Presses Universitaires de France: Paris, France, 2007; ISBN 10:213056027X.

36. Bogdan, R.C.; Biklen, S.K. Qualitative Research for Education: An Introduction to Theories and Methods, 5th ed.; Pearson Education: Hoboken, NJ, USA, 2007; ISBN 9780205482931.

37. Tuckman, B.W.; Harper, B.E. Conducting Educational Research, 6th ed.; Rowman \& Littlefield Pub, Inc.: Washington, DC, USA, 2012; ISBN 978-1-4422-0964-0.

38. Flick, U. An Introduction to Qualitative Research, 3rd ed.; Sage Publications: Austin, TX, USA, 2006; ISBN 9788536318523.

39. Zoller, U.; Scholz, R.M. HOCS paradigm shift from disciplinary knowledge (LOCS) to Interdisciplinary evaluative, system thinking (HOCS): What should it take in science-technology-environment-society-oriented courses, curricula, and assessment? Water Sci. Technol. 2004, 49, 27-36. https://doi.org/10.2166/wst.2004.0480.

40. Zoller, U.; Pushkin, D. Matching Higher-Order Cognitive Skills (HOCS) promotion goals with problem-based laboratory practice in a freshman organic chemistry course. Chem. Educ. Res. Pract. 2007, 8, 153-171. https://doi.org/10.1039/B6RP90028C.

41. Marcou, A. Coding strategic behavior in mathematical problem-solving. In Proceedings of the British Society for Research into Learning Mathematics, London, UK, 27 February-1 March 2007; pp. 54-57. Available online: https://bsrlm.org.uk/wpcontent/uploads/2016/02/BSRLM-IP-27-1-10.pdf (accessed on 11 December 2021).

42. Bono, E. Lateral Thinking; Random House: London, UK, 2014; ISBN 9780091955021.

43. Kuhn, T.S. The Essential Tension: Selected Studies in Scientific Tradition and Change; University of Chicago Press: Chicago, IL, USA, 1977; ISBN 0-226-45806-7.

44. Kuhn, T.S. The Structure of Scientific Revolutions, 3rd ed.; University of Chicago Press: Chicago, IL, USA, 1996; ISBN 9780226458083

45. Brennan, K.; Resnick, M. New frameworks for studying and assessing the development of computational thinking. In Proceedings of the Annual Meeting of the American Educational Research Association (AERA 2012), Vancouver, BC, Canada, 13-17 April 2012; pp. 1-25. Available online: http://scratched.gse.harvard.edu/ct/files/AERA2012.pdf (accessed on 12 December 2021).

46. Wing, J.M. Computational thinking. Commun. ACM 2006, 49, 33-36. https://doi.org/10.1145/1118178.1118215.

47. Wing, J.M. Computational thinking and thinking about computing. Proc. Math. Phys. Eng. Sci. 2008, 366, 3717-3725. https://doi.org/10.1098/rsta.2008.0118.

48. Bocconi, S.; Chioccariello, A.; Dettori, G.; Ferrari, A.; Engelhardt, K.; Kampylis, P.; Punie, Y. Developing computational thinking: approaches and orientations in K-12 Education. In Proceedings of the EdMedia 2016-World Conference on Educational Media and Technology, Vancouver, BC, Canada, 28 June 2016; Association for the Advancement of Computing in Education (AACE): Waynesville, NC, USA; pp. 13-18. Available online: https://www.learntechlib.org/primary/p/172925/ (accessed on 12 December 2021).

49. Zimmerman, B.J.; Pons, M.M. Development of a structured interview for assessing student use of self-regulated learning strategies. Am. Educ. Res. J. 1986, 23, 614-628. https://doi.org/10.3102/00028312023004614.

50. Carver, C.S.; Scheier, M.F. On the Self-Regulation of Behavior; Cambridge University Press: Cambridge, UK, 1998; ISBN 9781139174794.

51. Sitzmann, T.; Ely, K. A meta-analysis of self-regulated learning in work-related training and educational attainment: What we know and where we need to go. Psychol. Bull. 2011, 137, 421-442. https://doi.org/10.1037/a0022777.

52. Zoller, U.; Nahum, T.L. From Teaching to KNOW to Learning to THINK in Science Education. In Second International Handbook of Science Education, 2nd ed.; Fraser, B., Tobin, K., McRobbie, C., Eds.; Springer: Dordrecht, The Netherlands, 2012; Volume 24, pp. 209-330, ISBN 978-1-4020-9040-0.

53. Hmelo-Silver, C.E.; Ferrari, M. The Problem-Based Learning Tutorial: Cultivating Higher Order Thinking Skills. J. Educ. Gift. 1997, 20, 401-422. https://doi.org/10.1177/016235329702000405.

54. Hmelo-Silver, C.E. Problem-Based Learning: What and How Do Students Learn? Educ. Psychol. Rev. 2004, 6, $235-266$. https://doi.org/10.1023/B:EDPR.0000034022.16470.f3.

55. Russ, R.S.; Scherr, R.E.; Hammer, D.; Mikeska, J. Recognizing mechanistic reasoning in student scientific inquiry: A framework for discourse analysis developed from philosophy of science. Sci. Educ. 2008, 92, 499-525. https://doi.org/10.1002/sce.20264.

56. Soysal, Y. Middle School Science Teachers' Discursive Purposes and Talk Moves in Supporting Students' Experiments. Sci. Educ. 2021. https://doi.org/10.1007/s11191-021-00266-3.

57. Girault, I.; d'Ham, C.; Ney, M.; Sanchez, E.; Wajeman, C. Characterizing the experimental procedure in science laboratories: A preliminary step towards students experimental design. Int. J. Sci. Educ. 2012, 34, 825-854. https://doi.org/10.1080/09500693.2011.569901.

58. Harlen, W. Teaching, Learning and Assessing Science 5-12, 4th ed.; Sage Publications: London, UK, 2006; ISBN 1-4129-0871-X/14129-0872-8 (pbk). 
59. Li, Y.; Wang, K.; Xiao, Y; Froyd, J.E. Research and trends in STEM education: a systematic review of journal publications. Int. J. STEM Educ. 2020, 7, 11. https://doi.org/10.1186/s40594-020-00207-6.

60. Ince, E. An Overview of Problem-Solving Studies in Physics Education. J. Educ. Learn. 2018, 7, 191-200. https://doi.org/10.5539/jel.v7n4p191.

61. McDermott, T.; Hutchison, N.; Crick, R. The Evolution of HELIX: A Competency Model for Complex Problem Solving. In Proceeedings of the INCOSE International Symposium, Virtual Event, 17-21 July 2021; Volume 31, pp. 907-925. https://doi.org/10.1002/j.2334-5837.2021.00877.x.

62. European Space Agency (ESA). What is a Cansat?. Available online: https://www.esa.int/Education/CanSat/What_is_a_CanSat (accessed on 12 December 2021). 